\title{
Trends in discharge and flow season timing of the Onyx River, Wright Valley, Antarctica since 1969
}

\author{
Michael N. Gooseff, ${ }^{1}$ Diane M. McKnight, ${ }^{2}$ Peter T. Doran, ${ }^{3}$ and W. Berry Lyons ${ }^{4}$ \\ ${ }^{1}$ Department of Civil \& Environmental Engineering, Pennsylvania State University, University Park, PA 16802, USA (mgooseff@engr.psu.edu) \\ ${ }^{2}$ Institute of Arctic and Alpine Research, University of Colorado, Boulder, CO 80309-0450, USA (diane.mcknight@colorado.edu) \\ ${ }^{3}$ Department of Earth and Environmental Sciences, University of Illinois at Chicago, Chicago, IL, 60607 USA (pdoran@uic.edu) \\ ${ }^{4}$ Byrd Polar Research Center, Ohio State University, Columbus, OH, 43210 USA (lyons.142@osu.edu)
}

\begin{abstract}
Flow records at the two stream gauges on the Onyx River represent the longest actively collected environmental records in the McMurdo Dry Valleys, Antarctica. The downstream gauge, near Lake Vanda, has been collecting data since 1969, and the upstream gauge, at Lower Wright Glacier (LWRT), has collected data since 1972. We analyzed these records to assess the long-term trends in annual discharge, flow season length, flow season start, and flow season end. Our results indicate overall decreasing trends in annual discharge $\left(0.4 \times 10^{6} \mathrm{~m}^{3} /\right.$ decade at LWRT, 0.8 $\mathrm{x} 10^{6} \mathrm{~m}^{3} /$ decade at Vanda), and increasing flow season lengths (by $7 \mathrm{~d} /$ decade at LWRT, and $2.7 \mathrm{~d} / \mathrm{decade}$ at Vanda), influenced by earlier start and later end dates $(5.2$ and $0.8 \mathrm{~d} /$ decade, respectively at LWRT; $4.8,1.4 \mathrm{~d} / \mathrm{dec}$ ade, respectively at Vanda). This suggests that flow season climate patterns in the Dry Valleys are decreasing glacier melt intensity overall, but extending the period of meltwater generation.
\end{abstract}

Citation: Gooseff, M.G., D.M. McKnight, P.T. Doran, and W.B. Lyons (2007), Trends in discharge and flow season timing of the Onyx River, Wright Valley, Antarctica since 1969, in Antarctica: A Keystone in a Changing World - Online Proceedings of the 10th ISAES, edited by A.K. Cooper and C.R. Raymond et al., USGS Open-File Report 2007-1047, Short Research Paper 088, 4 p.; doi:10.3133/of2007-1047.srp088

\section{Introduction}

The McMurdo Dry Valleys make up an ice-free polar desert located on the western edge of McMurdo Sound (Fig. 1), dominated by open expanses of barren soils, alpine and piedmont glaciers, closed basin lakes, and incised stream channels. Mean annual air temperature in the Dry Valleys is $\sim-20^{\circ} \mathrm{C}$ and annual precipitation is generally less than $10 \mathrm{~cm}$ (Doran et al., 2002a). Glacial melt water streams flow during 4-12 week austral summer flow seasons, and receive little stream flow from snow melt (typically $<1 \%$ annually). Most streams terminate at perennially ice-covered closed-basin lakes, the levels of which vary with stream water inputs and surface ablation during the summer.

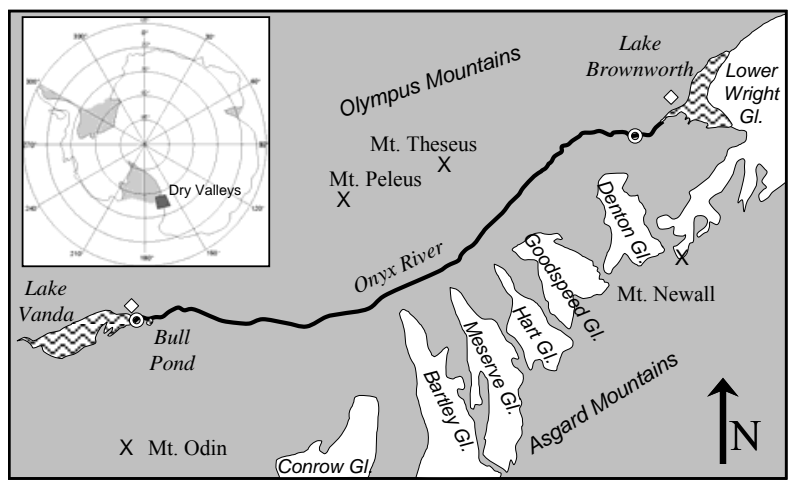

Figure 1. Location map of Wright Valley, Antarctica. The Onyx River flows from Lake Brownworth to Lake Vanda. Stream gauge locations are noted open circles. The Lower Wright (LWRT) stream gauge is located upstream, the Vanda stream gauge is downstream. Not necessarily to scale.
Stream flow in the Dry Valleys is dictated by source control factors (i.e. those that influence meltwater generation) and, during low flow years, the dynamics of the active layer adjacent to streams. The total energy balance at the glacier surface, a function of air temperature, wind speed, glacier albedo, and radiation, drives melt generation. Thus, the hydrology of the Dry Valleys is primarily driven by local climate (Chinn, 1993; Conovitz et al., 1998). Dry Valleys streams are underlain by an active layer generally less than $1 \mathrm{~m}$ deep (Gooseff et al., 2003; Conovitz et al., 2006). Previous studies of stream hydrology in the Dry Valleys found that longer streams generally have lower annual discharges (House et al., 1995), as a result of hyporheic storage of water in streambeds, which must be satisfied before stream flow can progress downstream. Thus during low-flow years, shorter streams contribute a larger proportion of water to terminal lakes than longer streams (Conovitz et al., 1998).

There is little data on high resolution climate cycles of the Dry Valleys prior to the 1960's. However, Bomblies et al. (2001) made a suite of simulations of stream flow generation constrained by an initial level of Lake Bonney (in Taylor Valley), measured by Scott's party in 1903, and modern lake level measurements, concluding that the local climate must have warmed during the $20^{\text {th }}$ century to result in the observed substantial lake level rise. The level of Lake Vanda was documented as rising by nearly $7 \mathrm{~m}$ from December 1968 to January 1987 (Chinn, 1993), an indication of a warming trend in the Dry Valleys during that period. Between 1986 and 2000, however, Doran et al. (2002b) noted that the Dry Valleys cooled, resulting in declining stream flow, lake levels, and soil biotic populations over that period. Despite this short cooling period, the substantial lake level rise of both Lake Bonney and Lake Vanda, and the documented warming 
pattern evident in long-term temperature record from nearby Marble Point (since 1981) and Scott Base (since 1958) as well as the isotopic records of snow pack of the Victoria Lower Glacier (Bertler et al., 2004; Doran et al., 2005) suggest that there has been increased energy applied to glacier surfaces to generate meltwater stream flow.

Flow records from two stream gauges on the Onyx River in Wright Valley, have been collected starting in 1969 and represent the longest environmental records in the Dry Valleys. We expect that long-term stream discharge records from the Onyx River, which flows from Lake Brownworth, adjacent to the Lower Wright Glacier (LWRT), to Lake Vanda, approximately $30 \mathrm{~km}$ to the west (Fig.1), should be an important indication of response to changing climate conditions in the Dry Valleys. Here we assess temporal trends in flow season characteristics of these flow records.

\section{Methods}

Onyx River discharge data were collected at LWRT and Vanda gauges by the New Zealand Antarctic Programme from 1969 to 1994, and by the McMurdo Long Term Ecological Research program from 1994 to present (see http://www.mcmlter.org for details on stream flow operation and data presented here). The Vanda stream flow record was initiated in 1969, whereas the LWRT flow record was initiated in 1972. Stream gauges are outfitted with $\mathrm{N}_{2}$ gas bubbler pressure transducers to determine stream stage at the gauging cross-sections. Our analysis is as dependable as the discharge records themselves; that is, we do not take into account possible errors in the record either at early or late season (e.g., flow initiation prior to seasonal operation of the gauge) or possible inaccuracies during the flow season.

We computed mean daily discharges for each day of flow for all flow seasons, and then computed means for each day of the year (October to February). Probability of flow for a given day during the flow season was computed as the number of years in which flow was recorded for that day, divided by the total record length in years. We performed linear regressions of the flow season length (total days), date of flow initiation, and date of end of flow to determine whether the records indicate any long-term changes in discharge dynamics. We also assess the statistical significance of these trends $(p<0.05)$. Our analysis ends in 2001, and annual flow records are missing for some years of each record: at LWRT, the records for water years 1987, 1988, and 1992; at Vanda, the records for water years 1978, 1992, 1994, and 1995.

\section{Results}

Analysis of both flow records suggest that mean daily discharges are comparable in magnitude at both gauges, though there is considerable variability, particularly at the starts and ends of flow seasons, when there are fewer discharge records than during the middle of the season (Fig. 2). Flow season lengths average 70 days at LWRT the stream gauge, and 58 days at the Vanda stream gauge. The average start date at the LWRT stream gauge is Nov. 30 , and at the Vanda gauge, Dec. 8, whereas the average end date at the LWRT stream gauge is Feb. 7, and the average end date at the Vanda stream gauge is Feb. 4. Annual discharge at the LWRT stream gauge averages $2.97 \times 10^{6} \mathrm{~m}^{3}$, and $3.45 \times 10^{6} \mathrm{~m}^{3}$ at the Vanda stream gauge. The 1978 water year record is the lowest flow of the record, with LWRT gauge recording $0.06 \times 10^{6} \mathrm{~m}^{3}$ over 24 days of flow, and no flow at Vanda gauge.

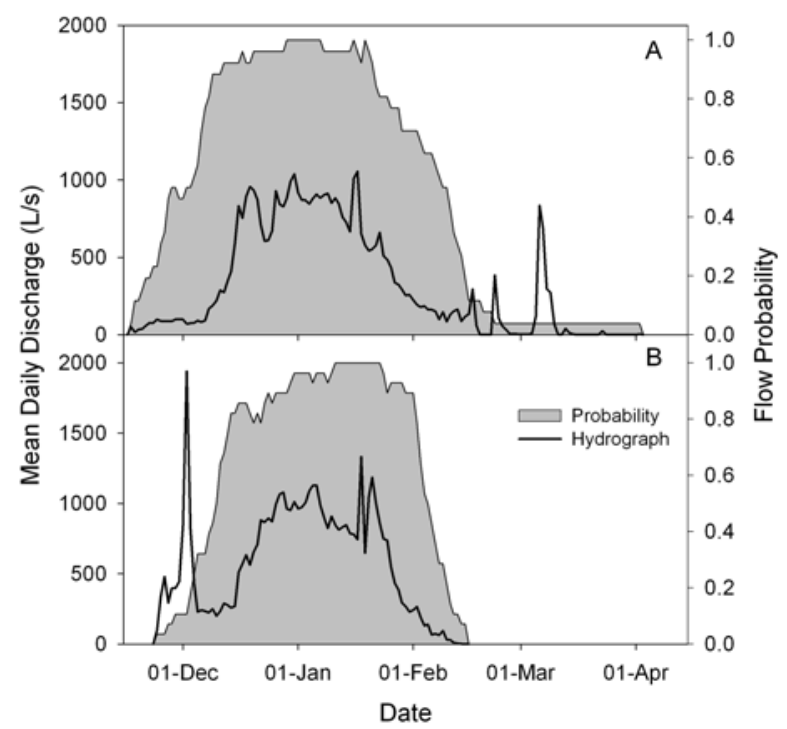

Figure 2. Average daily flows and probability of flow for each date over the periods of record for A) Onyx River at LWRT ( $n=26$ seasons) and B) Onyx River at Vanda ( $n=29$ seasons). Probabilities were computed as the number of years in which discharge was recorded, divided by the total number of years in the record.

Temporal trend analyses of the flow records suggest several decadal changes, with only two that were found to be statistically significant $(\mathrm{p} \leq 0.05)$. Analysis of the temporal change in annual discharge suggests that it is decreasing at a rate of $0.4 \times 10^{6} \mathrm{~m}^{3}$ per decade at LWRT, and $0.8 \times 10^{6} \mathrm{~m}^{3}$ per decade at Vanda (Figure $3 \mathrm{~A}$ ). Neither of these relationships is statistically significant, and it is clear that the temporal patterns of annual discharge do not demonstrate a clear trend. Our regressions suggest that flow season length is increasing, by 7 days per decade at LWRT and by 2.7 days per decade at Vanda (Figure 3B). The regression at LWRT is statistically significant $(p=0.02)$. Flow seasons are starting earlier in the year, by 5.2 days per decade at LWRT, a statistically significant regression $(p=0.001)$, and by 4.8 days per decade at Vanda (Figure 3C). Flow seasons appear to be ending later, 0.8 days per decade at LWRT, and 1.4 days per decade at Vanda (Figure 3D), though neither of these regressions is statistically significant. 


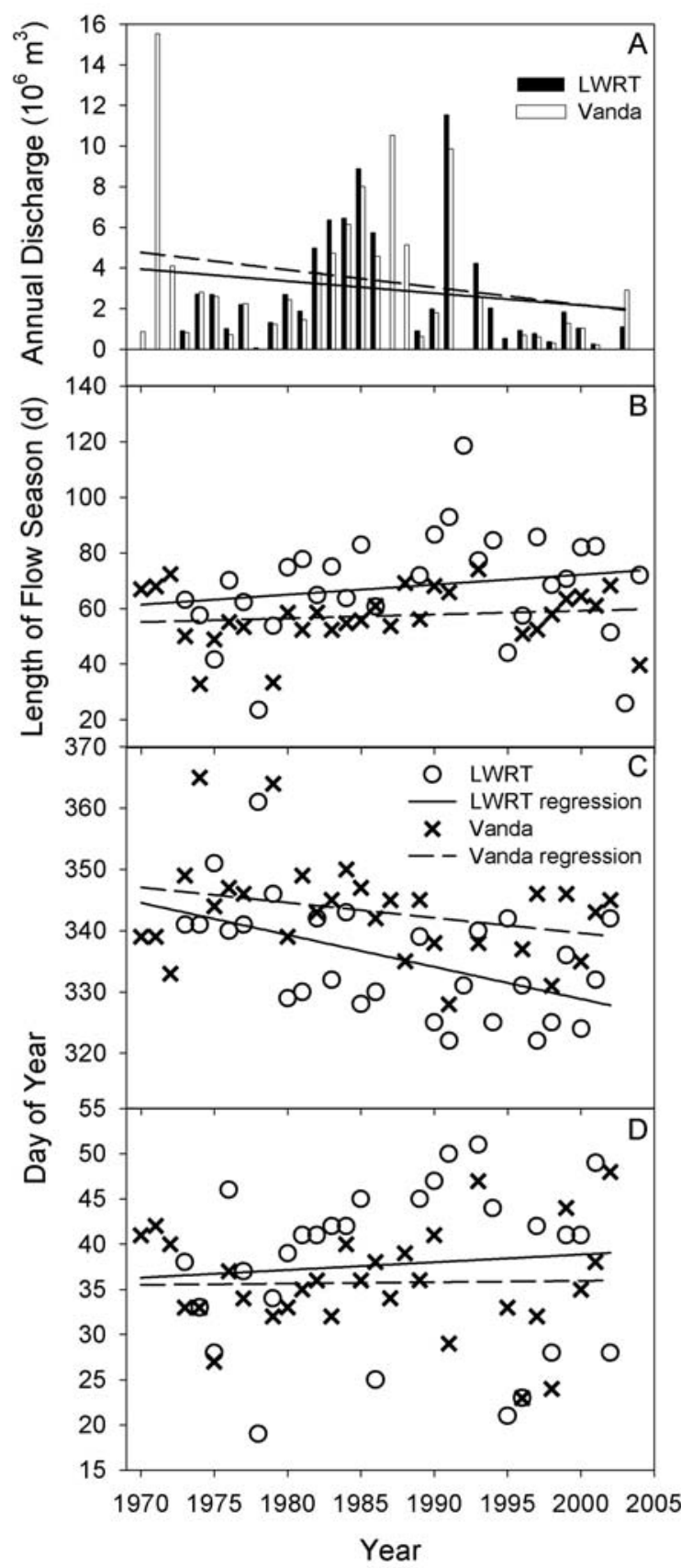

Figure 3. Regressions over entire flow records of $\mathrm{A}$ ) annual discharge $\left(\mathrm{R}^{2}=0.01, \mathrm{p}=0.57\right.$ for $\mathrm{LWRT}, \mathrm{R}^{2}=0.05$, $\mathrm{p}=0.27$ for Vanda), B) flow season length $\left(\mathrm{R}^{2}=0.19\right.$, $\mathrm{p}=0.02$ for $\mathrm{LWRT}, \mathrm{R}^{2}=0.06, \mathrm{p}=0.19$ for $\left.\left.\mathrm{Vanda}\right), \mathrm{C}\right)$ date of flow initiation $\left(\mathrm{R}^{2}=0.26, \mathrm{p}=0.001\right.$ for $\mathrm{LWRT}, \mathrm{R}^{2}=0.28$, $\mathrm{p}=0.08$ for Vanda), and D) date of end of flow season $\left(\mathrm{R}^{2}=0.01, \mathrm{p}=0.42\right.$ for LWRT, $\mathrm{R}^{2}=0.05, \mathrm{p}=0.62$ for Vanda). Note that the 1978 no-flow (0 days) data point for Vanda gauge is not shown in panel $\mathrm{B}$, but is included in the statistical analysis.

\section{Discussion}

The flow probabilities and average daily flow hydrographs from the LWRT and Vanda gauges indicate interesting patterns in discharge that should be considered in concert. For example, the daily flow hydrograph at Vanda indicates higher early season flows than those observed early in the season at LWRT and nearly immediate connection of flow from LWRT to Vanda. However, the probability of discharge at Vanda is much lower than that at LWRT into December, and as one expects, the rapid increase in probability of flow in December lags the rapid increase in probability of flow at LWRT several days (Fig. 2). Thus the high early season discharges indicated at Vanda are a consequence of an average of only 1 or 2 days of flow, which, in this case, were anomalously high discharge dates. These early season high discharges may be the result of errors in data collection (e.g. freezing of the $\mathrm{N}_{2}$ bubbler orifice at the gauge) or perhaps atypical rapid melt of snow or frozen stream flow from the previous season in the channel that quickly flushed through the Vanda stream gauge.

At the end of the flow season, probability of flow decreases first at Vanda, in early- to mid-February and then at LWRT approximately a week later (Fig. 2). Late season discharge at LWRT is higher than at Vanda, indicating that late season pulses of stream water that may occur in some years, is not regularly propagated all the way to the Vanda gauge. We temper this analysis with the knowledge that, while the New Zealand Antarctic Programme ran several late or over-winter field seasons at Vanda station, the McMurdo LTER scientists have not accessed these stream gauges (since 1993) in person beyond the first week of February. Thus, these very late season data are more likely to be in error than early season data because personnel are often in the field prior to streamflow initiation.

Despite the reported warming trends in the area since 1958 (Bertler et al., 2004), annual discharge of the Onyx River is apparently decreasing, but these trends are not statistically significant. Thus there does not appear to be an appreciable and/or consistent change in climate during the flow season (NDJF) that influences the total meltwater production in the Dry Valleys. Meanwhile, flow seasons are generally increasing in length, with a statistically significant increase in the LWRT record and shifts in both start and end of flow seasons, both of which are changing to increase the length of the flow season. Taken together, this suggests that while there may not be a general increase in the intensity of energy reaching the source glacier, perhaps during the height of the flow season, there is a change in climate over this area in the austral spring (likely $\mathrm{O}$ or $\mathrm{N}$ ), which is affecting the streamflow regime of the Onyx River.

When comparing the LWRT (upstream) flow initiation and cession to that of the Vanda gauge (downstream), it is worthy to note that the greater responses (steeper slopes of regressions) occur at LWRT, which is likely because it is closer to the source glacier, whereas the Vanda stream flow record is influenced by processes that may occur along the length of the reach, during transit from LWRT gauge. These processes 
include evaporation, possible stream discharge gains from meltwater streams of other glaciers in the Wright Valley, generally a minor contribution (Chinn, 1993), and possibly late season (post flow cession at LWRT gauge) drainage of the hyporheic zone along the length of the river.

\section{Conclusions}

Analysis of stream discharge records at the two stream gauges on the Onyx River in Wright Valley, Antarctica indicate that the flow season is generally shifting to earlier and longer flow seasons. Coincidently, there is a negative, though not significant, trend in total annual discharge over both records; together with the increasing flow season length, we propose that melt generation has decreased in intensity since the early 1970's, but that there is likely a positive change in the austral spring, as the lengthening flow seasons are generally starting earlier in the early austral summer rather than extending later into the late summer, compared to previous. Thus as a response to climate conditions, we interpret these changes to suggest that climate is changing to decrease the energy balance at glacier surfaces, perhaps at the peak of the flow season, but that positive shifts in the energy balance are occurring earlier in the flow season.

Acknowledgements. The authors appreciate the careful review comments of associate editor Peter Barrett, as well as reviewers Clive Howard-Williams, Martyn Tranter, and an anonymous reviewer. Their input greatly enhanced the quality of this manuscript. Data analyzed in this paper are the result of numerous scientists sponsored by New Zealand and United States Antarctic Science programs, including the McMurdo Long Term Ecological Research project. We appreciate their efforts to gather this valuable data set.

\section{References}

Bertler, N. A. N., P. J. Barrett, P. A. Mayewski, R. L. Fogt, K. J. Kreutz, and J. Shulmeister (2004), El Niño suppresses Antarctic warming. Geophys. Res. Let., 31, L15207, doi:10.1029/2004GL020749.

Bomblies, A., D. M. McKnight, and E. D. Andrews (2001), Retrospective simulation of lake-level rise in Lake Bonney based on recent 21-year record: indication of recent climate change in the McMurdo Dry Valleys, Antarctica, J. Paleolimnol., 25, 477-492.

Chinn, T. J. (1993), Physical hydrology of the Dry Valley lakes, in Physical and Biogeochemical Processes in Antarctic Lakes, edited by W. J. Green and E. I. Friedmann, pp. 1-51, AGU Antarctic Research Series, 59, Washington DC.

Clow, G. D., C. P. McKay, G. M. Simmons, and R. A. Wharton Jr. (1988), Climatological observations and predicted sublimation rates at Lake Hoare, Antarctica, J. Climate, 1, 715-728.

Conovitz, P. A., D. M. McKnight, L. H. MacDonald, A. G. Fountain, and H. R. House. (1998), Hydrological processes influencing streamflow variation in Fryxell Basin, Antarctica, in Ecosystem Dynamics in a Polar Desert: The McMurdo Dry Valleys, Antarctica, edited by J. C. Priscu, pp. 93-108, American Geophysical Union, Washington DC.

Conovitz, P. A., L. H. MacDonald, and D. M. McKnight (2006), Spatial and temporal active layer dynamics along three glacial meltwater streams in the McMurdo Dry Valleys, Antarctica, Arctic, Antarctic, Alpine Res., 38, 42-53.

Doran, P. T., C. P. McKay, G. D. Clow, G. L. Dana, A. G. Fountain, T. Nylen, and W. B. Lyons (2002a), Valley floor climate observations from the McMurdo dry valleys, Antarctica, 1986-2000. J. Geophys. Res., 107, 4772, doi:4710:1029/2001JD002045.

Doran, P. T., et al., (2002b), Antarctic climate cooling and terrestrial ecosystem response, Nature, 415, 517-520.

Doran, P. T., et al. (2005), Comment on "El Niño suppresses Antarctic warming" by N. Bertler et al., Geophys. Res. Lett., 32, L07706, doi:10.1029/2004GL021716.

Gooseff, M.N., D.M. McKnight, R.L. Runkel and B.H. Vaughn (2003), Determining long time-scale hydrologic flow paths in Antarctic streams. Hydrological Processes, 17, 1691-1710.

House, H.R., D.M. McKnight, and P. Von Guerard (1995), The influence of stream channel characteristics on streamflow and annual water budgets for lakes in Taylor Valley, Ant. J. U.S., 30, 284-287. 